\title{
HET KLIMAAT EN DE NATUURVERSCHIJNSELEN OP ONZE BOVENWINDSCHE EILANDEN
}

\author{
DOOR \\ IR. F. S. LANGEMEYER \\ (Hoofdingenieur van de Rijkswaterstaat)
}

Het klimaat van St. Maarten, St. Eustatius en Saba is, vooral gedurende de maanden November tot Mei goed. De Noord-Oostpassaat is in die maanden sterk overheerschend. De nachten zijn koel. Het komt voor dat de thermometer in den nacht daalt tot $68^{\circ}$ Fahrenheit of een enkele maal zelfs nog lager. Gedurende onze zomermaanden is de temperatuur belangrijk hooger, tot boven $90^{\circ}$ in de schaduw. Slechts zelden is de warmte zoo drukkend als zij op warme zomerdagen in Europa pleegt te zijn. Dit is overigens een gewoon verschijnsel in de tropen.

De meest voorkomende ziekteverschijnselen zijn, behalve mijnworm bij een deel der bevolking van St. Maarten, typhoïde koortsen en enteritis, meestal een gevolg van het gebruik van slecht drink- of wasch-water. Ofschoon op de eilanden zeer goede regenbakken aanwezig zijn, wordt toch door de medici aangeraden alle drinkwater te koken. Door de inheemsche bevolking geschiedt dit natuurlijk niet. Zij beweren immuun voor de genoemde ziekten te zijn, doch in tijden van langdurige droogte, wanneer de meeste regenbakken leeg zijn en putwater gedronken wordt, doen zich ook bij de inboorlingen de ziekteverschijnselen voor.

Ofschoon de gele-koorts-muskiet (stegoyma fasciata) de meest voorkomende muskiet is, is gele koorts sedert zeer langen tijd niet meer op de Bovenwindsche eilanden voorgekomen. De reeds genoemde mijnworm ziekte treedt vooral op in Simsonsbaai, een dorpje op St. Maarten met eene eigenaardige, blanke visschersbevolking, die eene, voor de tropen weinig hygiënischelevenswijze volgt.

De gemiddelde jaarlijksche regenval was in de 10 jarige periode 1909-1918, voorafgaande aan mijn twee-jarig verblijf (1918- 
1920) op St. Maarten $1030 \mathrm{~mm}$. Het droogste jaar in die periode was 1917 met $778 \mathrm{~mm}$., het natste jaar was 1916 met $1399 \mathrm{~mm}$. regen. Meestal vertoonen de maanden October en November de hoogste, de maanden Februari en Maart de laagste regencijfers.

De Noord-Oost-passaat waait in den regel met eene matige snelheid van 3 à 5 , volgens de windschaal van Beaufort. $\mathrm{Zij}$ kan, vooral in de eerste maanden van het jaar sterker worden, doch is slechts zelden gevaarlijk.

Gedurende de orkaanmaanden, waarmede de maanden JuliOctober worden aangeduid, waait de passaat veelal uit eene richting, die Zuidelijker is dan Oost. De windrichting is dan veel minder stabiel. Herhaaldelijk komen dan Zuidelijke tot ZuidWestelijke winden voor, die, zonder nog orkanen te zijn, zóó groote sterkte kunnen aannemen, dat de Groote Baai van St. Maarten, die tegen Zuidenwind geen bescherming biedt, tot eene woelige zee wordt.

„Met Juli begint de lucht meer en meer door de toenemende hitte uit te zetten, hetwelk voortduurt tot in October, een tijd, die men algemeen in West-Indië onderscheidt als de orkaanmaanden. Dit seizoen wordt in sommige jaren gekenmerkt door aanhoudende stilten, afgebroken door stormen uit het Zuiden met onweer en regen, en in andere jaren wederom door afwisselend harde windvlagen uit het Oosten en flauwe koelten, storm en stilte, regen en zonneschijn, alles binnen het tijdverloop van weinige uren, en weken achtereen voortdurende" ${ }^{1}$ ).

Aardbevingen van gevaarlijke afmetingen zijn op St. Martin zeldzaam. Wel komen er nogal eens kleine schokken voor, doch die zijn van weinig beteekenis. Saba en St. Eustatius hebben een ongunstiger reputatie.

De getijbeweging is in deze zeeën zeer zwak en onregelmatig. De amplitudo is zelden meer dan $1 \frac{1}{2}$ voet. .

Een ander verschijnsel zijn nog de zoogenaamde ,groundseas". Bij matige of zelfs zwakke winden kan de zee het aanzien van een zwaren storm vertoonen. Ook de Groote Baai van Philipsburg wordt ruw, zóó dat de zee met groote kracht breekt op de zandbank. Zekerheid omtrent de oorzaak van dit verschijnsel heb ik niet kunnen vinden. Het wordt toegeschreven aan aardschokken, doch ook aan verwijderde stormen: „These rollers are most frequent in the eastern part of the West-Indies, but

1) Beschrijving van het eiland Sint Eustatius" door A. H. BisschopGrevelink, kolonialen secretaris aldaar (1846). 
occur at times on all the islands. They frequently make landing dangerous and have been known to tear vessels from their anchorage and cast them ashore. They have been attributed to gales of wind prevailing at a distance, to interference between or union of the ordinary waves caused by the trades and to earthquake shocks"' ${ }^{1}$ ).

Het meest gevreesde van al de natuurverschijnselen is ongetwijfeld de West-Indische orkaan. Wel worden elders onder verschillende namen gelijksoortige winden aangetroffen, doch hier kunnen ze tot zeer groote hevigheid aangroeien.

,The greater part of the West-Indies are subject to violent circular storms, named hurricanes, which occur principally in August, September and October, when the tradewind is feeble and there are frequent calms, interrupted at times by violent squalls, rendering the navigation of the Carribean sea dangerous" 1).

De West-Indische orkaan kan worden ontleed in twee duidelijk te onderscheiden wind-bewegingen: $1^{\circ}$ de voortgaande beweging, $2^{\circ}$ de draaiende beweging. Het is, als het ware, een groote lucht-cilinder, die met eene ontzettende snelheid om zijn as wentelt, terwijl de, ongeveer vertikaal blijvende, as zich evenwijdig aan zich zelve voortbeweegt. De punten, van de as volgen daarbij een bepaalde baan.

Het ontstaan van zulk een orkaan houdt verband met de atmosferische gesteldheid over de geheele aarde gedurende de zomermaanden. Gedurende het warme seizoen op het Noordelijk halfrond bevindt zich een gordel van hooge druk tusschen $30^{\circ}$ en $40^{\circ}$ N.B., met toppen van grootere ontwikkeling boven de oceanen. De depressies zijn boven het zuidelijk gedeelte van Azië's vasteland en boven het Westelijk gedeelte van Noord-Amerika. Een nauw verband schijnt te bestaan tusschen de permanente hoogedruk-zônes in den Noordelijken Atlantischen Oceaan, zooals reeds door Captain Toynbee in zijn beschouwing van den typeerenden orkaan van Augustus 1873. (,Meterology of the North Atlantic in August 1873") is aangetoond. Bij het voortschrijden van het Noord-Atlantische hoog in het gebied der kalmten ontstaan wervelwinden, die hun baan vervolgen, verband houdende met de oogenblikkelijke meteorologische gesteldheid ${ }^{2}$ ).

$\left.{ }^{1}\right)$ „West Indies Pilot”, published by the Hydrographic Office under the Authority of the Secretary of the Navy (1918).

^) Oliver L. Fassig: „Hurricanes of the West-Indies” (Bulletin X van het U.S. Weatherbureau - Mrt. 1913). 
Volgens de "Convectional theory" wordt de oorzaak der wervelbeweging gezocht in een plaatselijk laag, waarnaar de omringende hoogedruk-velden afstroomen. Door de wenteling der aarde krijgt dit toestroomen naar het centrum een wervelende neiging. De lucht stroomt door dat centrum, de vortex, naar hoogere luchtlagen om zich daar weder naar buiten te bewegen. Het geheel is te vergelijken met een draaikolk in een rivier, die door den stroom voortbewogen wordt ${ }^{1}$ ).

Waarschijnlijk worden ontelbare van dergelijke draaiwinden gevormd, doch de factoren om hen tot een storm te doen aangroeien zijn gelukkig niet zoo vaak aanwezig, zoodat ze zich weder verspreiden, vóór dat ze tot kracht zijn gekomen.

Groeit zoo'n draaiende wind wel tot stormkracht aan, dan kan de snelheid der draaiende beweging tot $45 \mathrm{~m}$. à $50 \mathrm{~m}$. per sec. bedragen. „The cyclone and especially the tropical cyclone is characterized by a vast eddy on an average of 300 miles in diameter, of extraordinary violence in the gusts of wind ( 90 miles per hour and sometimes more) and carrying necessarily with it a relative vacuüm, which increases from the periphery to the center or vortex. This rarefication of the air in so large an area implies a lack of equilibrum in the atmosphere which by the law of compensation represents an excess of air in one or more isolated places surrounding the hurricane".

De voortgaande beweging van den storm wordt dus in de breedten binnen den keerkring beheerscht door dezelfde invloeden als die, waaraan de passaatwinden onderhevig zijn. Ofschoon de baan van het Centrum van elke storm zeer verschillend is, valt daarbij toch wel eenige regelmatigheid op te merken, zoodra men de banen van verschillende stormen naar de maanden van hun optreden, met elkaar vergelijkt.

In de fig. zijn de gemiddelde breedten van 135 stormen uit de jaren 1876-1910, naar de maanden van den orkaantijd geteekend. De gemiddelde banen hebben parabolische vormen. Elke baan kan men verdeelen in drie takken: $a$, eene iets, Noordelijker dan zuiver Oost-West gerichte tak, welke geheel onder invloed staat van de tropische luchtstreek; $b$, de top van de parabool, welke ontstaat op $20^{\circ}$ à $30^{\circ}$ N.B. en $c$, eene naar het Oosten gerichten tak, die in de gematigde zône terecht komt, waar de storm al spoedig zijn hevig karakter verliest.

1) William H. Alexander: „Hurricanes: especially those of PortoRico and St. Kitts” (Bulletin $\mathrm{n}^{\circ} 32$ van het U.S. Weatherbureau 1902). 


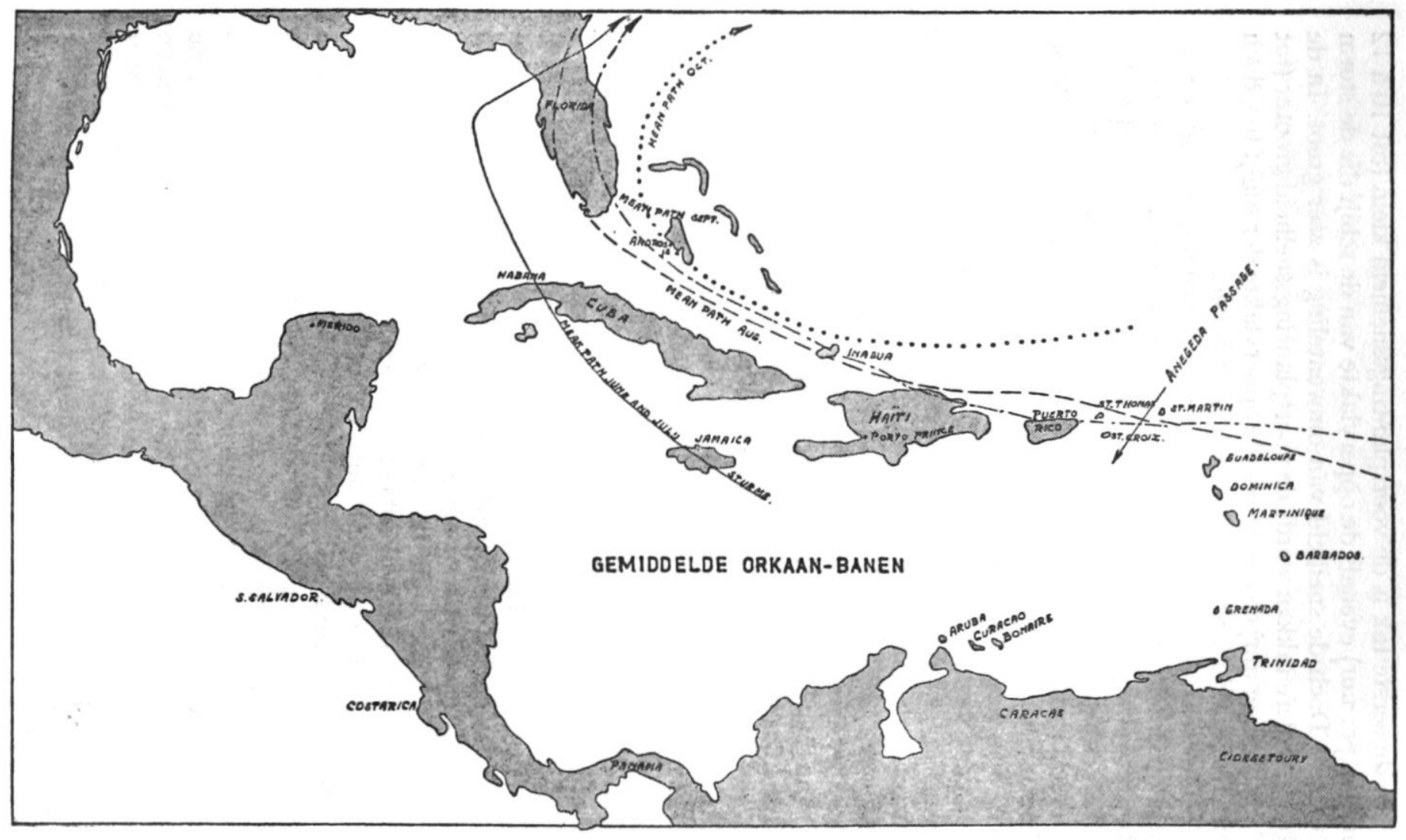

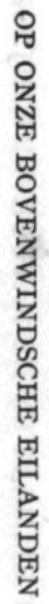

Gem. orkaan banen $n$. de maanden (waarnemingen v. h. U. S. Weather Bureau). 
In de eerste tak is de voortplantingssnelheid klein (tot 10 à 12 mijlen per uur) evenals de oppervlakte van de schijf die de storm beslaat. Doch de snelheid van omwenteling is zeer groot. In de beide andere takken wordt de voortplantingssnelheid grooter (tot 19 mijlen per uur) en neemt ook de oppervlakte der schijf toe, doch vermindert de kracht der wentelende winden.

De oorsprong van den orkaan en de ombuiging liggen niet altijd op dezelfde plaats. Vaak is de eerste tak slechts kort of ontbreekt zelfs geheel. Meestal is de oorsprong Oostelijk van de Antillen. Volgens den Cubaanschen pater. Dr. Benito Vines („Cyclonic circulation and the translating movement of the WestIndian hurricanes") bestaat er eene wet voor de normale richting van de baan op de verschillende data en breedten: De algemeene vorm van de baan blijft voor de verschillende perioden dezelfde, maar de geografische positie verandert. Het punt van oorsprong wordt Oostelijker naarmate het seizoen vordert tot ongeveer half Augustus. Daarna heeft het de neiging wederom meer westwaarts te komen.

Van de 135 stormen, waaruit de gemiddelde banen der figuur werden samengesteld, viel er 1 geheel buiten het orkaanseizoen. De overigen waren verdeeld als volgt: in Mei 1, in Juni 8, in Juli 5, in Augustes 33, in September 43, in October 42, en in November 2. De plotselinge aangroeiing der frequentie in Augustus in de even plotselinge afname in November zijn specifieke kenmerken dezer tropische stormen: Het meest active seizoen begint in de tweede helft van Augustus en duurt ongeveer tien weken.

Zijn de orkanen werkelijk ontzettende natuurverschijnselen, één eigenschap hebben ze, die hen gunstig van andere rampen onderscheidt: Ze komen zelden zonder waarschuwing. De eerste en meest betrouwbare voorteekenen komen van den barometer.

In West Indië is de barometerstand als regel zeer constant. Dagelijks doen zich twee schommelingen voor van ongeveer $\frac{1}{2} \mathrm{~mm}$. Elke afwijking van deze normale schommelingen moet met achterdocht worden bekeken. Als eerste teeken van een naderende orkaan wordt vaak een abnormale rijzing waargenomen. De storm is dan nog ver weg, vermoedelijk wel meer dan 800 K.m. Dan begint de barometer te schommelen tengevolge van onregelmatige en onderling botsende luchtstroomen. Daarna begint de daling, die hoe langer hoe sneller wordt, naar mate de storm in hevigheid toeneemt. $\mathrm{Na}$ het passeeren van het middelpunt van den storm treedt een herstel van den barometerstand in.

De zee vertoont reeds eenigen tijd van te voren een eigenaardig 
strak uiterlijk en ze is zeer helder. Dat wordt afgewisseld met het uiterlijk van een kokende pot. Bij het naderen van den storm treden er lange, rollende golven op. Ook de wolken geven eene aanwijzing. Zoo is het voorkomen van in een punt convergeerende cirri het teeken van een naderend storm-centrum. De lucht is diep blauw, de zon lijkt bij zonsondergang te steunen op zijn stralen en heeft een bleek en ziekelijk licht. Bewolkte en wolkenlooze luchten wisselen elkaar snel af. De atmosfeer is eerst droog, daarna afwisselend droog en vochtig. Soms wordt zij zeer warm en zwoel als in een oven, met heiig zicht. Geluiden worden zeer ver gehoord.

Reeds eenige dagen vóór den storm wordt de wind onstandvastig. Als de barometer stijgt ten gevolge van het passeeren van den pericyclonischen ring treedt eene kalmte in, gevolgd door een gradueel aangroeiende wind, die eerst in vlagen blaast met oogenblikkelijke kalmten.

Natuurlijk kan men pas uit het optreden van meerdere voorteekenen tegelijk tot de waarschijnlijkheid van het naderen van een orkaan concludeeren.

Men beweert op St. Martin, dat dit eiland minder aan orkanen is blootgesteld dan St. Thomas. Ofschoon dit voor de waargenomen stormen wel juist schijnt te zijn, zoo is er toch geen reden dit ook voor de toekomst te voorspellen. De Benedenwindsche eilanden liggen buiten het eigenlijke orkaangebied, al krijgt men er ook daar wel eens een staartje van.

Wanneer een orkaan een onzer Bovenwindsche eilanden, bijvoorbeeld St. Maarten, zou bezoeken dan kan het zijn dat de vortex de plaats van waarneming passeert, of wel dat zij ten Noorden of ten Zuiden daarvan blijft. In het eerste geval zal de storm beginnen te waaien uit het N.O. tot N. Deze windrichting blijft, met eenig verloop naar het Oosten, tot de vortex voorbijgaat. Hoe dichter de vortex nadert, des te grooter wordt het barometrisch verhang en des te sterker wordt de wind.

Als het stormcentrum passeert, treedt er een plotselinge kalmte in. De zware, loodgrijze wolken klaren op en misschien zelfs wordt het uitspansel even blauw. Maar al spoedig begint de wind met volle kracht uit het Zuiden tot Zuid-Westen te waaien. Doch nu gaat de barometer rijzen en de storm vermindert in kracht, terwijl de richting misschien iets Zuidelijker wordt.

Dit alles gaat gepaard met hevige regenbuien, soms ook onweer. Het stormcentrum heeft slechts een geringe oppervlakte in vergelijking met de horizontale doorsnede van den geheelen 
storm, die een gemiddelde diameter van wel $500 \mathrm{Km}$. kan hebben. Wanneer het storm-centrum ten Zuiden van de waarnemingsplaats passeert, is het verloop een weinig anders. De windrichting is dan dadelijk meer Oostelijk gericht, en wel te Oostelijker naarmate de vortex verder Zuidelijk blijft. Met het sterker worden van den storm, draait de wind door het Oosten naar het Zuiden. Nadat de Oostelijke richting bereikt is, neemt de windkracht af en nadert de storm zijn einde.

In het derde geval eindelijk, dat de vortex in het Noorden voorbijgaat, is de beginrichting meer Westelijk dan zuiver Noord, te Westelijker naarmate de vortex verder verwijderd blijft. De wind krimpt naar het Zuid-Westen en bereikt in de buurt van de zuiver Westelijke richting zijn maximale kracht.

In het bovenstaande is verondersteld, dat de voortgaande beweging zuiver Oost-West gericht zou zijn. De waarnemingsplaats ligt dus in de eerste tak. Dit is bij onze Bovenwindsche eilanden regel. Evenwel wijkt de werkelijke voortgaande beweging iets daarvan af, waarmede dan ook weer kleine variaties van de, in het waarnemingspunt optredende windrichtingen, gepaard gaan.

Het aantal waargenomen orkanen was in het genoemde tijdvak 1876 - 1910 gemiddeld 4 per jaar. In werkelijkheid waren de jaren 1877,1897 en 1905 geheel vrij van stormen en werden in 1886 en 1887 telkens 11 van deze natuurverschijnselen in of om de Caraibische zee waargenomen. Natuurlijk zijn niet aldeze stormen even destructief en zal het zelfs in enkele gevallen en op enkele punten moeilijk geweest zijn een orkaan als zoodanig te herkennen. Onder de auspiciën van het U.S. Weatherbureau is een uitgebreide waarnemings- en waarschuwingsdienst voor deze gevreesde winden ingericht. Uit de waarnemingen op verschillende plaatsen worden de noodige conclusies getrokken.

Het aantal stormen voor een bepaalde plaats is natuurlijk belangrijk minder dan bovengenoemde cijfers, welke voor den geheelen Archipel gelden. De frequentie is afhankelijk van de geografische ligging. Door de golf van Yucatan, de Florida-straat en over de Zuidelijke punt van Florida gaan relatief de meeste stormen.

Merkwaardige aanteekeningen over 40 stormen, gedurende de jaren 1515-1900 (waarvan er evenwel 20 na 1800 werden opgeteekend) werden te Porto-Rico aangetroffen. Voor die plaats was dus de frequentie voor de laatste eeuw 1 storm per 5 jaren. Te St. Kitts werden tusschen 19 September 1623 en 18 September 1899 opgeteekend 64 orkanen, derhalve 1 per 4 à 5 jaren. Het kortste interval was tusschen 7 Augusteus 1899 in 8 September 
1899 en het langste tusschen 2 September 1859 en 21 Augustus 1871. Te St. Eustatius bestaat eene beschrijving van 43 orkanen 1717-1908. Van orkanen te St. Martin heb ik geen verzamellijst kunnen vinden, wel enkele aanteekeningen. Hun aantal en hevigheid zal niet veel van die te St. Eustatius en St. Kitts verschild hebben. Herhaaldelijk werd het zout over geheel Philipsburg verspreid. Natuurlijk deden vele ware of verdichte verhalen van vroegere orkanen de ronde. Geen wonder dat zulk een verschijnsel leeft in de volksziel. Zoo verhaalde men dat het geheele dak van een der huizen door de wind werd afgerukt en over honderden meters werd medegevoerd.

Het meest leefde in het volksgeheugen de orkaan van 21 September 1819, een der hevigste die ooit gewoed heeft. Daar het in 1919 juist een eeuw geleden was vreesde men ook voor dat jaar zware stormen. Ze zijn echter uitgebleven. Door die orkaan verzandden in één nacht de mond nabij Marigot van het Simsonbaai-lagoen en werd vlak bij het dorp Simsonbaai een nieuwe mond geslagen. Op het Nederlandsch gedeelte van het eiland werden 81 menschen gedood en werden velen gekwetst. Ook de materieele schade aan vee, gewassen en gebouwen was groot. Bijna alle negerhutten en 348 grootere gebouwen werden vernield.

Tot slot moge eene aanhaling uit het dagboek van Commandeur Cantzlaar, die den eigenlijken orkaan op het Fransche gedeelte van St. Martin meemaakte, hier volgen om de verschrikking van zulk een ramp duidelijker voor oogen te brengen:

„In den morgen van gisteren de wind beginnende op te steken „en uyt het Noorden te waaien, ondervonden wij binnen deze „kolonie eene geweldigen storm, die in den namiddag toekwam „tot een der hevigste orkanen, die bij menschenheugenis immer ,,in dit Eyland gewoed hebben, vergezeld van stortregen, donder, „blixem en aardbevingen en voortdurende tot vier uur in den „morgen van heden. Mij met het aanbreken van den dag naar dit gedeelte terug begeevende, wierd ik ooggetuige dezer alge-,, „meene ellende en zag ik niets dan verwoesting en onderschey„den personen vervoeren, die van onder de puynhoopen zwaar "gekwetst waren gehaald en die zich beroofd vonden van klee„ding en woningen. De grond, waarop het dorp Simpsonsbaay "gebouwd is, was doorgebroken en de zee had zich met de daar„agter zijnde pan vereenigd zoodat de meeste woningen waren „weggespoeld en onderscheyden personen daarbij het leven ver"loren hebben. De werken der Plantagien, die ik passeerde waren 
„meerendeels vernield en het suykerriet ter nedergeslagen, de „hoofdplaats Philipsburg vond ik genoegzaam in een puynhoop „veranderd en ik vond de nog levenden bezig met het bezorgen „der gekwetsten, der lijken, en opspeuren van het weynige dat „hun overgebleven en onder de puynen en elders verspreyd was. „Het gouvernementshuys, geheel van steen gebouwd, was tot op „de kelders ingestort en vond ik al mijn meubelen en huysraad „verpletterd, bedden en linnengoed bedorven of verscheurd voor soo verre het nog van onder de puynhoopen konde gered „worden. Mijn boeken, papieren enz. de publieke administratien „en mijne particuliere zaken concerneerende vernield, verspreyd, „door de regens geheel bedorven en gedeeltelijk door den wind „verloren, de kerk tot op den grond ingestort, de gallerij en het „gedeeltelijk dak van het Raadhuys weggewaaid en vernam ik, dat de casernen op het fort Amsterdam waren ingestort en het "dak van het blokhuys op het fort Willem de Eerste was wegge"waaid met de aldaar staande ligte gebouwen".

Zwolle 24 Februari 1934 